. 


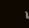




\section{ARPA-NBS Program of Research on High Temperature Materials and Laser Materials}

U.S. ARTMENT OF OMMERCE National Bureau of indards 


\section{NATIONAL. BUREAU OF STANDARDS}

The National Bureau of Standards ${ }^{1}$ was established by an act of Congress March 3, 1901. The Bureau's overall goal is to strengthen and advance the Nation's science and technology and facilitate their effective application for public benefit. To this end, the Bureau conducts research and provides: (1) a basis for the Nation's physical measurement system, (2) scientific and technological services for industry and government, (3) a technical basis for equity in trade, and (4) technical services to promote public safety. The Bureau consists of the Institute for Basic Standards, the Institute for Materials Research, the Institute for Applied Technology, the Center for Computer Sciences and Technology, and the Office for Information Programs.

THE INSTITUTE FOR BASIC STANDARDS provides the central basis within the United States of a complete and consistent system of physical measurement; coordinates that system with measurement systems of other nations; and furnishes essential services leading to accurate and uniform physical measurements throughout the Nation's scientific community, industry, and commerce. The Institute consists of a Center for Radiation Research, an Office of Measurement Services and the following divisions:

Applied Mathematics-Electricity-Heat-Mechanics-Optical Physics-Linac Radiation ${ }^{2}$ - Nuclear Radiation ${ }^{2}$ - Applied Radiation ${ }^{2}$ - Quantum Electronics ${ }^{3}$ Electromagnetics ${ }^{3}$ - Time and Frequency ${ }^{3}$ - Laboratory Astrophysics ${ }^{3}$-Cryogenics ${ }^{3}$.

THE INSTITUTE FOR MATERIALS RESEARCH conducts materials research leading to improved methods of measurement, standards, and data on the properties of well-characterized materials needed by industry, commerce, educational institutions, and Government; provides advisory and research services to other Government agencies; and develops, produces, and distributes standard reference materials. The Institute consists of the Office of Standard Reference Materials and the following divisions:

Analytical Chemistry-Polymers-Metallurgy-Inorganic Materials-Reactor Radiation-Physical Chemistry.

THE INSTITUTE FOR APPLIED TECHNOLOGY provides technical services to promote the use of available technology and to facilitate technological innovation in industry and Government; cooperates with public and private organizations leading to the development of technological standards (including mandatory safety standards), codes and methods of test; and provides technical advice and services to Government agencies upon request. The Institute also monitors NBS engineering standards activities and provides liaison between NBS and national and international engineering standards bodies. The Institute consists of the following technical divisions and offices:

Engineering Standards Services-Weights and Measures-Flammable FabricsInvention and Innovation-Vehicle Systems Research-Product Evaluation Technology-Building Research-Electronic Technology-Technical AnalysisMeasurement Engineering.

THE CENTER FOR COMPUTER SCIENCES AND TECHNOLOGY conducts research and provides technical services designed to aid Government agencies in improving cost effectiveness in the conduct of their programs through the selection, acquisition, and effective utilization of automatic data processing equipment; and serves as the principal focus within the executive branch for the development of Federal standards for automatic data processing equipment, techniques, and computer languages. The Center consists of the following offices and divisions:

Information Processing Standards-Computer Information-Computer Services -Systems Development-Information Processing Technology.

THE OFFICE FOR INFORMATION PROGRAMS promotes optimum dissemination and accessibility of scientific information generated within NBS and other agencies of the Federal Government; promotes the development of the National Standard Reference Data System and a system of information analysis centers dealing with the broader aspects of the National Measurement System; provides appropriate services to ensure that the NBS staff has optimum accessibility to the scientific information of the world, and directs the public information activities of the Bureau. The Office consists of the following organizational units:

Office of Standard Reference Data-Office of Technical Information and

Publications-Library-Office of Public Information-Office of International Relations.

\footnotetext{
${ }^{1}$ Headquarters and Laboratories at Gaithersburg, Maryland, unless otherwise noted; mailing address Washington, D.C. 20234

2 Part of the Center for Radiation Research.

8 Located at Boulder, Colorado 80302 .
} 
UNITED STATES DEPARTMENT OF COMMERCE

Maurice H. Stans, Secretary

NATIONAL BUREAU OF STANDARDS - Lewis M. Branscomb, Director

\section{NBS TECHNICAL NOTE 574}

ISSUED MAY 1971

Nat. Bur. Stand. (U.S.), Tech. Note 574, 44 pages (May 1971)

CODEN: NBTNA

\section{ARPA-NBS Program of Research on High Temperature Materials and Laser Materials}

Reporting Period

July 1 to December 31, 1970

Edited by A. D. Franklin and H. S. Bennett

Inorganic Materials Division

Institute for Materials Research

National Bureau of Standards

Washington, D.C. 20234

Supported by the

Advanced Research Projects Agency

of the Department of Defense

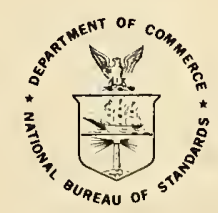

NBS Technical Notes are designed to supplement the Bureau's regular publications program. They provide a means for making available scientific data that are of transient or limited interest. Technical Notes may be listed or referred to in the open literature.

For sale by the Superintendent of Documents, U.S. Government Printing Office, Washington, D.C., 20402. (Order by SD Catalog No. C 13.46:574). Price 50 cents. 

Page

1. Introduction .................... 1

2. High Temperature Materials Program ............ 2

2.1. Objectives and Summary of Program in High

Temperature Materials .......... 2

2.1.1. Objectives .............. 2

2.1.2. Summary of Progress to Date ....... 4

2.2. Project Summaries in High Temperature Materials . . 5

2.2.1. Diffusion in Oxides ......... 5

2.2.1.1. Crystal Growth from Vapor .... 5

H. S。 Parker and C. A. Harding

2.2.1.2. Diffusion in Refractory Materials . 6

A. L。Dragoo

3. Laser Materials Program ............... 11

3.1. Introduction to Laser Materials . . . . . . 11

3.2. Objectives and Summary of Program in Laser Materials 。 11

3.2.1. Objectives . . . . . . . . . . . 11

3.2.2. Summary of Progress to Date ........ 13

3.2.2.1. Characterization of Laser Materials 13

3.2.2.2. Damage to Laser Materials .... 13

3.3. Project Summaries in Laser Materials ........ 14

3.3.1. Damage to Laser Materials ....... 14

3.3.1.1。 Laser Induced Damage Studies ... 14

Albert Feldman, Roy Waxler, and

Deane Horowitz

3.3.1.2. Effect of Microdomains Formed by

Liquid/Liquid Immiscibility Upon

the Damage Threshold of Glass . . 22

Wolfgang Haller and Hank Dardy

3.3.2. Appendix: Trip Reports ........ 26

3.3.2.1. Foreign Trip Report, H。S。Bennett • 26

3.3.2.2. Domestic Trip Report, H。S。Bennett 35 
ARPA-NBS PROGRAM OF RESEARCH ON HIGH TEMPERATURE MATERIALS AND LASER MATERIALS

Work Performed at the National Bureau of Standards Supported by the Advanced Research Projects Agency, Department of Defense (ARPA Order 373-62)

Reporting Period July 1 to December 31, 1970

Edited by A. D。 Franklin and H. S. Bennett

Progress reports are given for projects on the growth of ultra-pure $\mathrm{Al}_{2} \mathrm{O}_{3}$ crystals, the development of a mass spectrometer-based sectioning technique for measuring oxygen diffusion in oxides, the development of a precision facility for measuring the threshold energy in a laser beam producing damage in a transparent substance, and the study of the factors influencing this damage threshold in glass.

Key words: $\mathrm{Al}_{2} \mathrm{O}_{3}$; crystal growth; damage threshold; glass; high temperature materials; laser; oxides; oxygen diffusion; pure materials; sapphire. 


\section{INTRODUCTION}

The National Bureau of Standards, with the support of the Advanced Research Projects Agency (Office of Materials Sciences) of the Department of Defense, is carrying out a program of research on High Temperature and Laser Materials. The overall objective of this program is to provide some of the key elements needed by DoD in its purusit of new technology through research and development. These elements include:

i. The preparation and characterization of materials needed for critical studies where exacting criteria of chemical purity, crystalline perfection, etc。must be met if progress is to be made,

ii. The development of new measurement techniques where these are required, and the acquisition of critically-needed data on certain material properties, and:

iii. The elucidation of the basic mechanisms contributing to or limiting the use of materials under extreme conditions (e.g. high temperatures, high intensity laser light, etc。)。 A summary of the results achieved in the period July 2 to December 31, 1970, is given here.

Among the many areas of Defense Technology where advances of the kind described above are needed, this Program has focussed upon two. Ceramics are used in many ways, and many problems in their use relate ultimately to mass transport effects. Highly important improvements could be made by developing a firmer understanding of and control over mass transport processes in oxides. Since NBS has had considerable experience in this field, it is a natural one upon which to concentrate a portion of this Program. 
The other area of concentration was introduced into this Program several years ago in response to an urgent need seen by the Sponsor. As laser power has moved upward, laser beams, especially pulsed beams of very short pulselength, have been found to damage the materials (amplifier laser rods, windows, lenses, prisms, and other optical elements) through which the beams must pass. Not only must a better understanding be developed of the processes leading to the several types of damage so far observed, but also there is a need for more reproducible techniques for studying these damage processes and for characterizing the response of given materials with respect to them。

Corresponding to these two areas of concentration, this Report is divided into two parts, High Temperature Materials and Laser Materials. Each part will open with a brief summary of objectives and accomplishments, followed by detailed Project progress reports.

\section{HIGH TEMPERATURE MATERIALS PROGRAM}

2.1. Objectives and Summary of Program in High Temperature Materials 2.1.1. Objectives

The operation of rocket and jet engines involves exposing metals at high temperatures to oxidizing conditions, and raises the problem of oxidation protection of high temperature refractory metal structural components. This same problem, currently for superalloy turbine blades, is posed again by jet engines. The oxidation protection of metals requires some form of barrier layer to prevent diffusion. This layer, either applied or developed by the early stages of oxidation itself, will most likely be an oxide, and will function to keep the metal and oxygen apart. It can work only if the diffusion rates of oxygen and metal atoms through the layer are small enough. Thus, the strategy for the development of oxidation protection of otherwise susceptible metals at high temperatures will depend in part on being able to control the rates of diffusion, and therefore, in having data on the diffusion rates themselves. 
Diffusion in oxides is important to other classes of DoD problems. Thus improvements in the reliability and efficiency of military communication, computer, and radar circuitry could be made if ceramic magnetic and ferroelectric components could be made more reproducible and reliable. Because such important properties as initial susceptibility and coercive force of ferrites, and dielectric and piezoelectric properties of ceramic ferroelectrics, are very sensitive to the microstructural features (porosity, grain size) controlled by sintering, the strategy for improvement here requires control over sintering in these ceramics. The same is true of ballistic response of ceramic armor. The development of transparent armor requires new techniques for the suppression of grain growth during otherwise complete sintering, mainly of $\mathrm{Al}_{2}{ }^{0} 3^{\circ}$

Since sintering in ceramics is mainly brought about by diffusion processes, the development of successfu1, long-range strategies to meet these DoD needs rests in part on knowledge of the rates of diffusion of metal and oxygen atoms in oxides.

Reliable techniques for measuring oxygen diffusion rates are not yet available, and therefore reliable data for oxygen diffusion does not exist for any save a few oxides. Thus one objective of this program is to develop a reliable technique for measuring the rate of diffusion of oxygen in oxides.

Further, diffusion rates are notoriously sensitive to impurities, and strategies for control require knowledge of the basic rate in the pure material and of the way various classes of impurites influence it. This in turn requires very pure crystals for study. To date, almost no oxide crystals have been prepared pure enough to reveal the intrinsic diffusion rates. The second objective in this area is to prepare intrinsically pure crystals of those materials for which mass transport data is sorely needed. The first candidate has been $\mathrm{Al}_{2}{ }^{0}{ }_{3}$, an important constituent in many ceramics, in particular for ceramic armor. 
2.1.2. Summary of Progress to Date

In previous work on the preparation of very pure crystals of $\mathrm{Al}_{2} \mathrm{O}_{3}$, the growing technique had been perfected and extremely pure crystals prepared. The probably sources of residual impurities had been identified. During the past period, modifications to the growing apparatus have been made designed to eliminate or strongly lower the remaining major impurities, particularly silicon. Ultra-pure aluminum has been obtained as source material. During the next reporting period growth will be attempted of crystals sufficiently pure to make possible the study of the intrinsic mass transport processes in $\mathrm{Al}_{2} \mathrm{O}_{3}$.

In the project on the development of a technique for the measurement of Diffusion Coefficients in Oxides, the diffusion anneal apparatus has been used to perform diffusion anneals of Zno crystals for Prof. A. Heuer of Case-Western Reserve University, working under another ARPA contract. Work has continued on developing a method for moving tracer $0^{18}$ from ground-off sections of the sample into the massspectrometer for analysis. An investigation was made of one possible method whereby graphite is reacted with the specimen to form $\mathrm{C} 0$, which is then converted to $\mathrm{CO}_{2}$ by a hot iron filament before introduction into the mass spectrometer. The conversion step appears to be too slow to allow use of the method. Instead, reaction with halogen fluorides to release oxygen for direct analysis will be tried. The necessary equipment has been designed and is being assembled. 
2.2. Project Summaries in High Temperature Materials

2.2.1. Diffusion in Oxides

2.2.1.1. CRYSTAL GROWTH FROM VAPOR

H. S. Parker and C.A. Harding

Inorganic Materials Division

Institute for Materials Research

The objectives of the program are: first, the growth of aluminum mono- and bicrystals of sufficient physical perfection and chemical purity for use as research materials; second, the reduction of both cation and anion impurities to sufficiently low levels to permit meaningful property measurements at the intrinsic level, and third, the extension of the technique to other materials of interest.

During the present reporting period, growth of single and bicrystals has continued and specimens have been supplied to Dr. Heuer at Case Western Reserve University. A further characterization of chemical purity under consideration at the present time is that of precise measurement of thermal conductivity at low temperatures. This will be pursued further if samples of sufficient size can be grown.

Modifications have been made in the seed holding technique for bicrystal growth which should result in better maintenance of alignment during the critical first growth cycle. A very small amount of high purity alumina cement is placed over one end of the seeds and prefired to $1400^{\circ} \mathrm{C}$ in a separate furnace with the seeds held in the proper orientation by alumina blocks. This has the further advantage of leaving more seed surface available for growth because less cement is needed to provide the required strength.

Poor quality growth in one bicrystal run, the crystal having the appearance of being grown under a very high supersaturation, was traced to a minute leak in the alumina growth chamber. In the pressure range over which the system operates, 0.3 to 5 Torr, the leak was too 
small to be detected under dynamic pumping conditions. Rate of pressure rise in a blanked-off system is now used to establish the vacuum tight integrity of the system before growth.

New heaters have been designed and wound for the two vapor growth furnaces. The present temperature control system operates by sensing current level and maintaining a constant current through the furnace. The new heaters incorporated a second concentric winding of small diameter tungsten wire, electrically isolated from the heater winding. This auxiliary winding will form the temperature sensitive arm of a bridge circuit, thus the control system will respond directly to temperature changes rather than current changes, providing better temperature control.

Preliminary testing of components of the new vapor growth system is in progress and it is anticipated that the new system will be fully operative in about one month's time. A supply of zone refined aluminum metal of nominal $99.9999 \%$ purity has been obtained from a commercial source. Upon completion of a growth run with this source material, a series of comparative analyses will be made.

A paper describing the growth and characterization of ultra-high purity aluminum oxide crystals by the vapor growth technique is in preparation。

2.2 .1 .2 . DIFFUSION IN REFRACTORY MATERIALS

A。 L。Dragoo

Inorganic Materials Division

Institute for Materials Research

The objectives of this program are to measure and to interpret diffusion of oxygen in single crystal oxides. Experimentally these two objectives consist of (1) extending the sensitivity of present techniques 
so that the ${ }^{18} 0$ distribution in a single crystal sample can be measured, (2) comparing the results of these concentration profile measurements with measurements of the rate of exchange of ${ }^{18} 0$ between the gas phase and the oxide crystal, (3) determining the dependence of the diffusion rate on temperature, oxygen partial pressure, impurities in the solid, etc. and (4) obtaining reliable diffusion and exchange coefficients. Oxygen self-diffusion in oxides provides a tool for uncovering the type of point defects involved in ionic migration in oxides and the energies required for the formation and motion of these defects. Since oxygen diffusion can be the controlling step in the solid state reaction and sintering of oxides, the diffusion coefficients are needed for interpretation and estimation of these rates.

Our initial studies have been carried out on single crystals of rutile because of its relatively high oxygen self-diffusion rate along the $\mathrm{C}$ axis in the neighborhood of $1200^{\circ} \mathrm{C}$. Our results at 1275 and $1350^{\circ} \mathrm{C}$ agree well with those of Haul and Dumbgen(1) who studied oxygen exchange with single crystal fragments and with those of Lees, et a1(2) who use a proton activation technique on ${ }^{18} 0$-diffused single crystals.

The problem of platinum deposition during diffusion anneals in the platinum furnace tube was eliminated by hanging a series of heat shields above the specimen. I estimate that the thermal isotopic fractionation which may occur should be no more than a fraction of a per cent.

Having established the gaseous exchange technique, the next step is the development of an analytical procedure for determining the distributions of ${ }^{16} 0$ and ${ }^{18} 0$ in the oxide crystals. A possible technique for liberating $\mathrm{O}_{2}$ from the small amounts of powder removed from the crystal during sectioning is the reaction of the oxide powder with hot carbon in molten platinum. Precise measurement of the isotopic ratios necessitates the conversion of the $\mathrm{CO}$ to $\mathrm{CO}_{2}$ prior to the mass spectrometer analysis. 
Oishi and Kingery(3) reported the catalytic decomposition of co to $\mathrm{CO}_{2}$ using a red-hot, electrically heated, iron filament previously reduced by hydrogen. The $\mathrm{CO}_{2}$ produced by the reaction

$$
2 \mathrm{CO}(\mathrm{g})=\mathrm{CO}_{2}(\mathrm{~g})+\mathrm{C}(\mathrm{s})
$$

was collected on the liquid nitrogen cooled walls of the tube during the course of the reaction which required 2 to 4 hours to complete depending upon the surface conditions of the iron wire.

I attempted to increase the conversion rate by using a dense bundle of iron wire which had a much larger surface area than the coiled iron filament. The wire was contained in a quartz tube and was heated externally, as indicated in Fig. 1. After reducing the wire with hydrogen, a small quantity of $\mathrm{CO}$ (10 to $20 \mu$ moles at $6 \times 10^{-3}$ to $12 \times 10^{-3} \mathrm{~N} / \mathrm{m}^{2}$ pressure) was admitted to the tube. The gas and iron wire were heated; the temperature of the heater was controlled between $780^{\circ}$ and $1180^{\circ} \mathrm{C}$ for periods of 2 to 4 hours. The lower end of the tube, filled with glass balls to provide a large surface area, was cooled with liquid nitrogen. The pressure was observed with a thermocouple gauge. I did not observe any pressure drop which would have occurred if $\mathrm{CO}_{2}$ had been formed and had been frozen out.

Since this reaction, which is the critical step in the graphitereduction procedure, did not promise a quick success, the procedure has been abandoned for the much more thermodynamically favorable bromine pentafluoride reaction in order to liberate $0_{2}$ from the oxide samples.

Two diffusion anneals were carried out on $\mathrm{ZnO}$ specimens for Dr. Heuer of Case-Western Reserve University. 


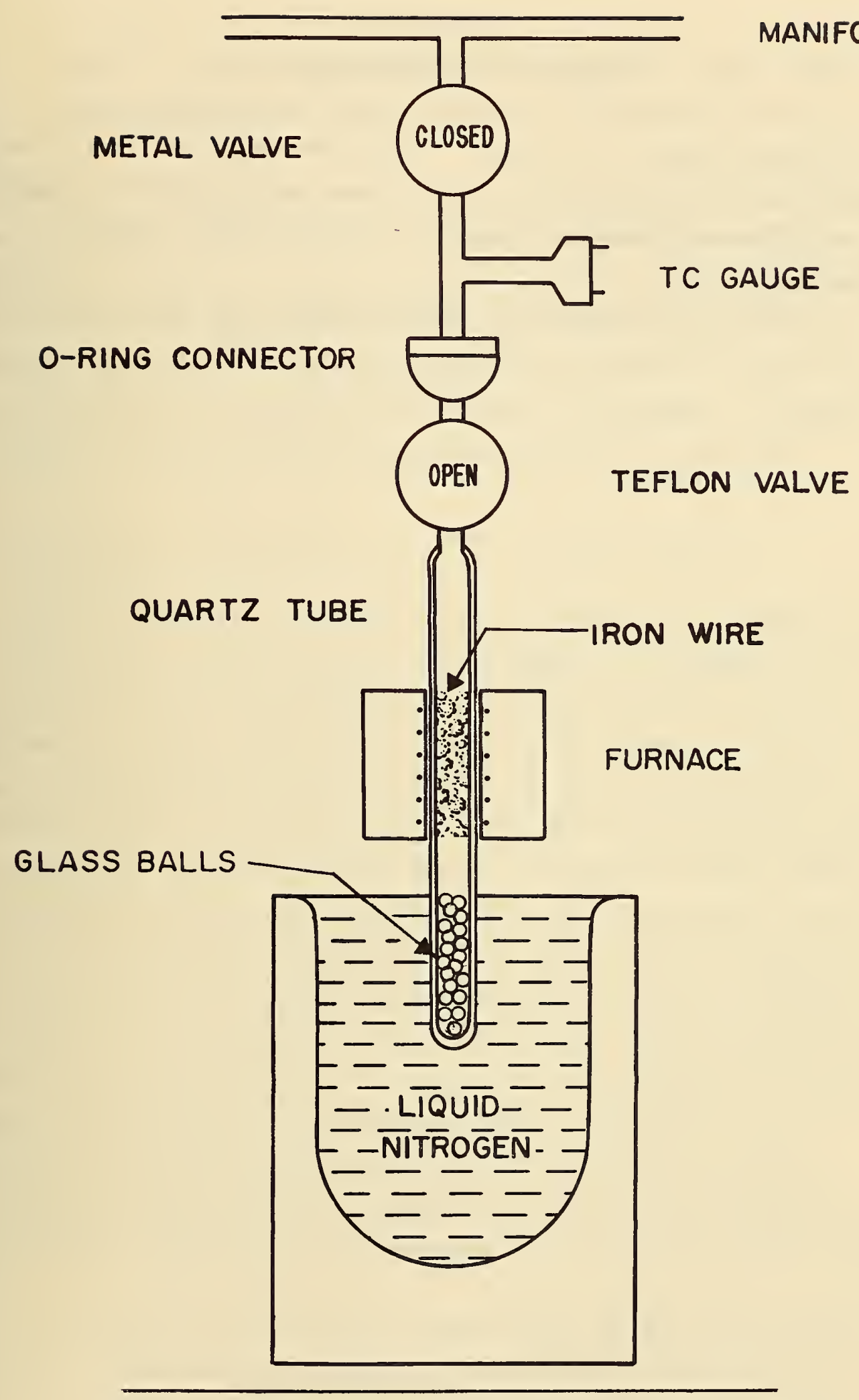

MANIFOLD

QUARTZ TUBE

Fig. 1. Apparatus for the Conversion of $\mathrm{CO}$ to $\mathrm{CO}_{2}$. 


\section{References}

1. R. Haul and G. Dưmbgen, Jo Phys. Chem. Solids 26, 1 (1965)

2. D。 Lees, J。M. Calvert and A。J. Derry, "A Technique using Resolance Capture of Protons to Study Oxygen Diffusion in Titanium Dioxide," paper presented to the Thomas Graham Memorial Symposium on Diffusion Processes, University of Strathclyde, Glasgow, Scotland, 1969。

3. Y。Oishi and W。D。Kingery, $F_{\circ}$ Chem. Phys。 33, 480 (1960) 


\section{LASER MATERIALS PROGRAM}

3.1. Introduction to Laser Materials

The National Bureau of Standards, with support from the Advanced Research Projects Agency (Office of Materials Sciences) of the Department of Defense, is carrying out a program of research on laser materials. This program includes studies to characterize laser materials, to define and evaluate damage measurements in laser materials, and to investigate the degradation of laser performance. A summary of the results achieved during the reporting period is given here.

3.2. Objectives and Summary of Program in Laser Materials. 3.2.1. Objectives

One of the important factors which is limiting the advance of ultra high power laser technology is the failure or degradation of laser materials due to optically induced damage. In the past, the empirical approach to laser materials has been adequate. That is, the damage or degradation to laser materials has been circumvented by equipment design or by a cut-and-try improvement in the laser materials. This problem of optically induced damage now poses a serious threat to the successful application of laser devices to an important class of needs of the Department of Defense. This fact has been recognized and the Advanced Research Projects Agency supports research to improve the performance of laser materials. The convening of three committees to examine the optical damage to laser materials illustrates the present concern and importance of solving this class of problems. These committees are the Subcommittee II of ASTM Committee F-1, the Institute for Defense Analysis Studies, and the National Materials Advisory Board Committee on the Fundamentals of Damage in Laser Glass.

The success of these efforts depends upon having the knowledge and proper skills available when they are needed. In the case of laser technology, they include the science and techniques of laser 
materials preparation and characterization and of the measurement and evaluation of those properties which are relevant to the damage and degradation of lasers. It is the overall objective of the present NBS program on laser materials to identify some of the more important problems concerning damage and degradation of lasers and to provide the necessary advances in those areas for which NBS possesses the competence to do so. These efforts will be directed mainly toward providing the techniques for the preparation and characterization of laser materials to be used in tests for the measurement and evaluation of material properties pertinent to the damage and degradation of lasers, for the tabulation of key damage data, and for the improvement in the knowledge and skills necessary to advance the performance of lasers.

In pursuit of this program, a continuing attempt is being made to analyze the technological problems associated with high performance lasers and the materials from which they are constructed, and to distill from this analysis major scientific problems whose solutions would advance laser technology. In addition, the problems chosen should fall within areas in which NBS has available competence. Also, the number of problems included in the program should be kept small enough so that each one can be approached in a reasonably compreshensive manner.

The level of effort on laser materials has been reduced at the suggestion of the sponsor. This has been accomplished by terminating the projects on the Characterization of Laser Materials and on the Degradation of Laser Materials. In accordance with these changes and the above mentioned criteria, the present program consists of the project on Damage to Laser Materials. Damage and Degradation as used here are distinguished in that Damage is localized and occurs during the course of a very few pulses whereas Degradation implies the much more gradual and general deterioration of performance over many pulses. There may, of course, be some overlāp. 
3.2.2. Summary of Progress to Date

3.2.2.1. Characterization of Laser Materials

The projects on the Characterization of Laser Materials have been terminated. The results of the past work have been or will be published in the open literature. In particular, four papers have been written:

i) R. M. Waxler and E. N. Farabaugh, Photoelastic Constants of Ruby, NBS Journal of Research, Sec.A (Physics and Chemistry) 74A, No. 2, 215 (1970)。

ii) R. M. Waxler, Laser Glass Composition and the Possibility of Eliminating Electrostrictive Effects, to be published in the April 1971 issue of the IEEE $\mathrm{J}$ 。 of Quantum Electronics 。

iii) R. M. Waxler, et al., Optical and Mechanical Properties of some Nd-doped Laser Glasses, accepted for publication in the NBS J. of Research, Sec. A (Physics and Chemistry)。

iv) R.F. Blunt, G. A. Candela, R。A. Forman, A. H. Kahn, and B。W. Mangum, Magnetic Susceptibility and Optical Studies of $\mathrm{Cr}^{3+}$ in $\mathrm{Al}_{2} \mathrm{O}_{3}$ (Ruby); submitted to the Journal of Applied Physics, Jan.1971.

\subsubsection{Damage to Laser Materials}

Inclusion damage (bulk) has been a serious source of difficulty for the laser systems engineer concerned with ultra-high power pulses。 Although surface damage and intrinsic damage (self-focusing or beam trapping) contribute additional problems, these are at present apparently not as great an obstacle to the advance of laser technology as the inclusion damage is. A laser glass damage test facility is being constructed at NBS to study the damage problem and to attempt to bring some unity to the great proliferation of damage data. This test facility will center around a one gigawatt neodymium glass laser system and will be used to develop standards for performing meaningful (reproducible) measurements on the damage mechanisms which are produced by high energy laser pulses. The construction of this facility includes detailed characterization of the laser beam. Near field intensity profiles of this laser have been made and have been compared with other neodymium lasers. These profiles will be used as a guide to make 
certain that the NBS laser beam has a satisfactorily homogeneous beam. The necessity for having a homogeneous beam in order to obtain meaningful damage measurements has been stressed at several conferences.

During this report period, with the benefit of valuable consultations with Dr.J. Emmett and Mr。J。 McMahon (Naval Research Laboratory) and with Dr。J。Swain (Lawrence Radiation Laboratory, Livermore), the present NBS Nd-glass laser is being improved in order to ensure sufficient beam uniformity and reproducibility to allow meaningful damage threshold measurements 。

A theoretical model for studying the thermal stresses produced by inclusions in laser materials has been developed. Three papers on this problem will be published; namely,

i) H. S. Bennett, Absorbing Centers in Laser Materials, to be published in the February 1971 issue of the J. of Applied Physics.

ii) H. S. Bennett, Inclusions in Laser Materials, to be published in the NBS Journal of Research, Sec. A (Physics and Chemistry).

iii) H. S. Bennett, Heat Diffusion near Absorbing Centers in Laser Materials, to be published in the NBS Journal of Research, Sec. A (Physics and Chemistry)。

3.3. Project Summaries in Laser Materials

3.3.1. Damage to Laser Materials

\subsubsection{LASER INDUCED DAMAGE STUDIES}

Albert Feldman, Roy Waxler, and Deane Horowitz

Inorganic Materials Division

Institute for Materials Research

\section{Objectives}

The objectives of this work is the development of a laser test facility to determine intrinsic bulk damage threshold parameters of laser glasses used in pulsed high energy laser systems. To achieve this objective, it is necessary to produce a laser beam in the TEM mode. 
This work complements the work at the Naval Research Laboratory which is concerned with developing high power laser systems and testing for inclusion damage.

\section{Technica1 Approach}

The present report period has been spent testing and evaluating the performance of the laser system, described in our previous report (NBS Technical Note 565, 1971), which had been delivered by a commercial supplier.

Burn pattern tests made on the oscillator rod showed the beam to be extremely inhomogeneous and non-reproducible from shot to shot. It was thus necessary to examine every element in the laser system, and to improve a number of them.

Figure 1 shows a shadowgraph of the oscillator rod. The structure at the center of the pattern indicates damage which occurred in the antireflection coating on the rod during preliminary testing of the system. The rod was returned to the manufacturer for repolishing and has been returned to us.

Figure 2 shows Twyman-Green interferograms of the two tent polarizers in our system. Both indicate they are acting as weakly positive elliptical lenses in the system. Figure 3 shows a Twyman-Green interferogram of the first amplifier rod in our system. The jog in some of the fringes indicates that there is an abrupt change in optical path in the rod which might adversely affect any attempt to obtain diffraction limited operation of the system. The second amplifier rod appears to have reasonable optical path uniformity as shown by the relatively evenly spaced straight interference fringes in Fig. 4.

The Pockels cell, which was returned to the manufacturer for improvement of the shuttering characteristics, was also found to have damaged wind ows. 
After consultations with Dr. J. Emmett and Mr. J. McMahon of the Naval Research Laboratory we have come to the conclusion that this commercial system requires extensive modification.

It is necessary for every component of the oscillator system to be of extremely high optical quality because any optical distortion is magnified by the many passes which the laser light must make in the oscillator cavity. Thus a cavity with the fewest number of elements is desirable. We have therefore decided to Q-switch by means of a rotating mirror and hence eliminate two polarizer stacks and the Pockels cell. In addition, a specially selected oscillator rod has been ordered which will produce less than $1 / 10$ wave of wavefront distortion with the $632.8 \mathrm{~nm}$ HeNe laser 1ine。

\section{Present Activities}

We are presently assembling components for construction of a Twyman-Green or Mach-Zender interferometer. These will be used for examining all optical components to be used in our laser system, and also to measure the optical distortions introduced into the laser rods by pumping. It is planned that these tests will be performed under dynamic conditions.

\section{Acknowledgments}

We would like to thank Dr. J. Emmett and Mr. J. McMahon of the Naval Research Laboratory for their valuable assistance in this work. The Twyman-Green interferograms and the shadowgraphs were done by Fred Rosberry of NBS. 


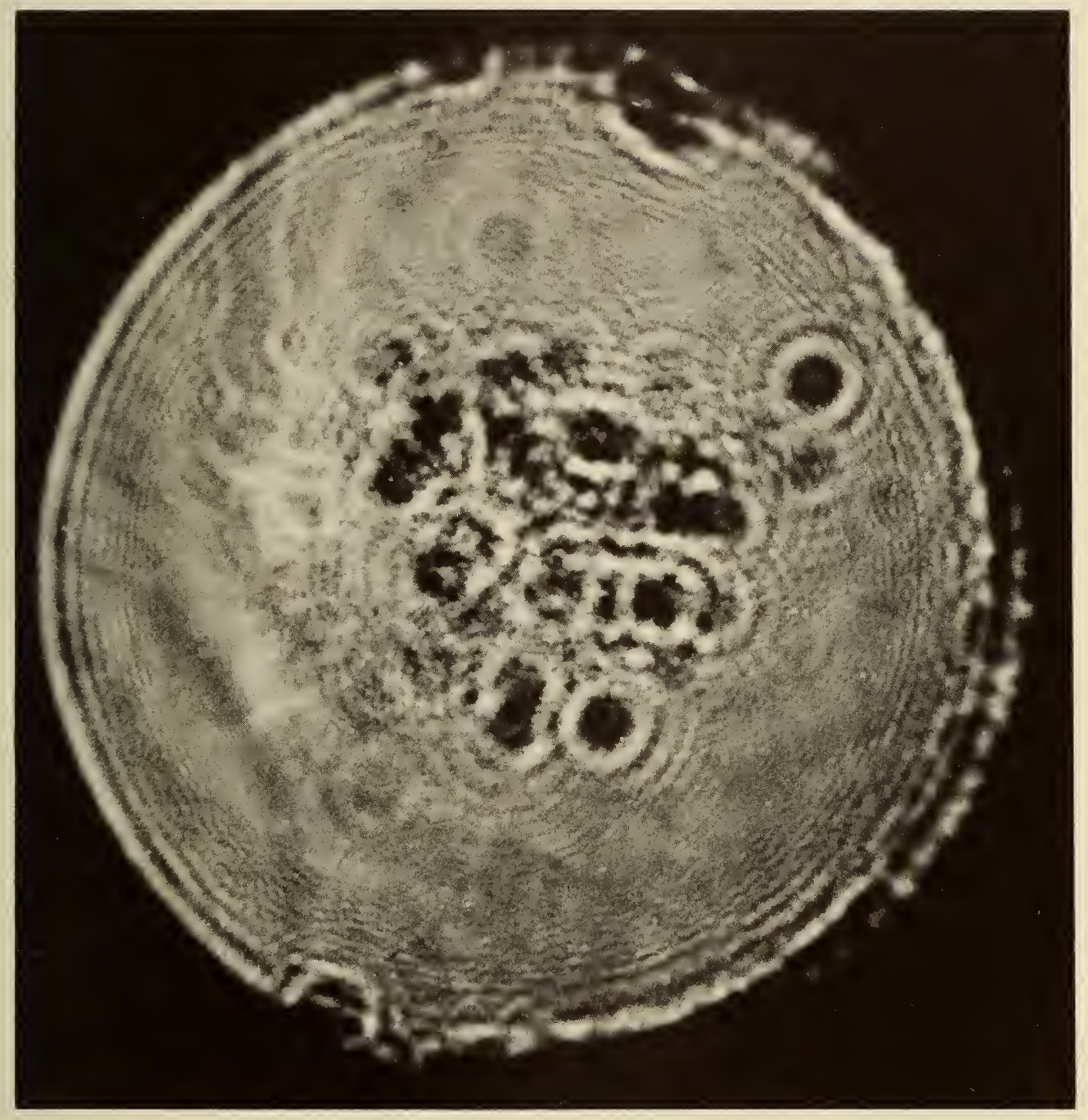

Fig. 1. Shadowgraph of oscillator rod. The structure at the center is caused by damage in the antireflection coating. 


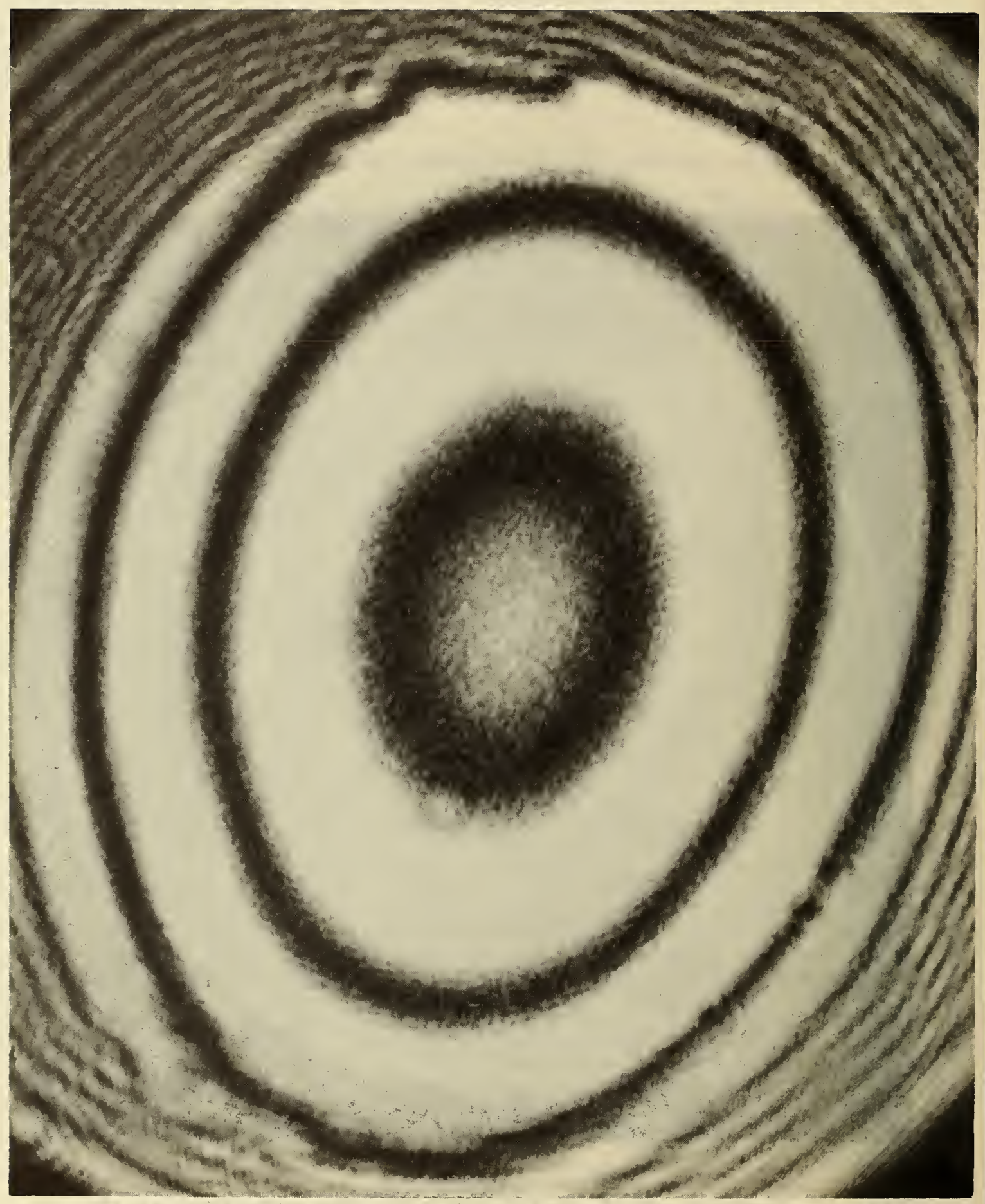

Fig. 2(a) Twyman-Green interferogram of ten plate tent polarizer in oscillator system. Three elliptical fringes are shown which indicate that the polarizer is acting as a weak positive lens. 


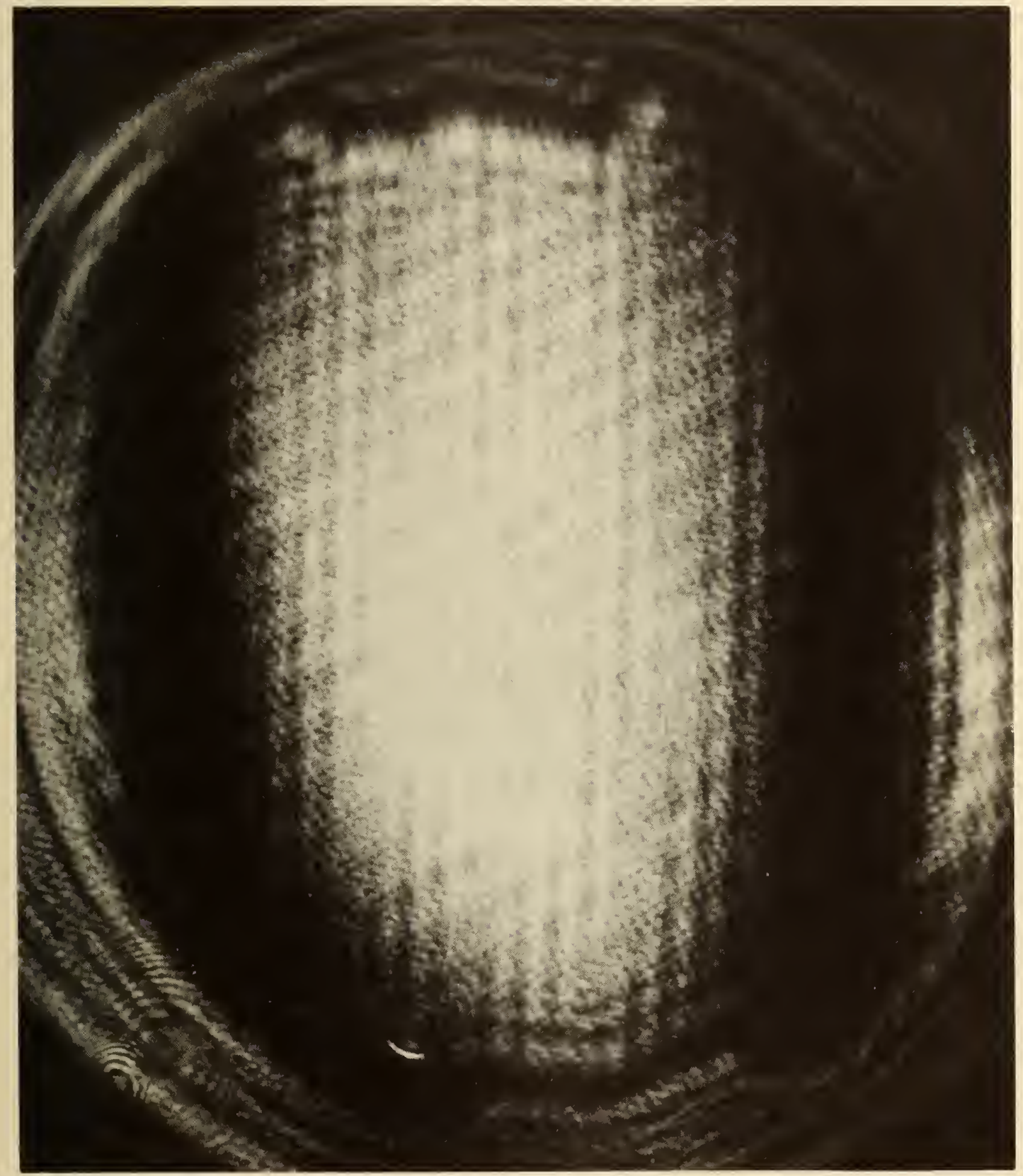

Fig. 2(b). Twyman-Green interferogram of five plate polarizer stack in oscillator system. Two fringes are seen. This polarizer is acting as a weak cylindrical lens. 


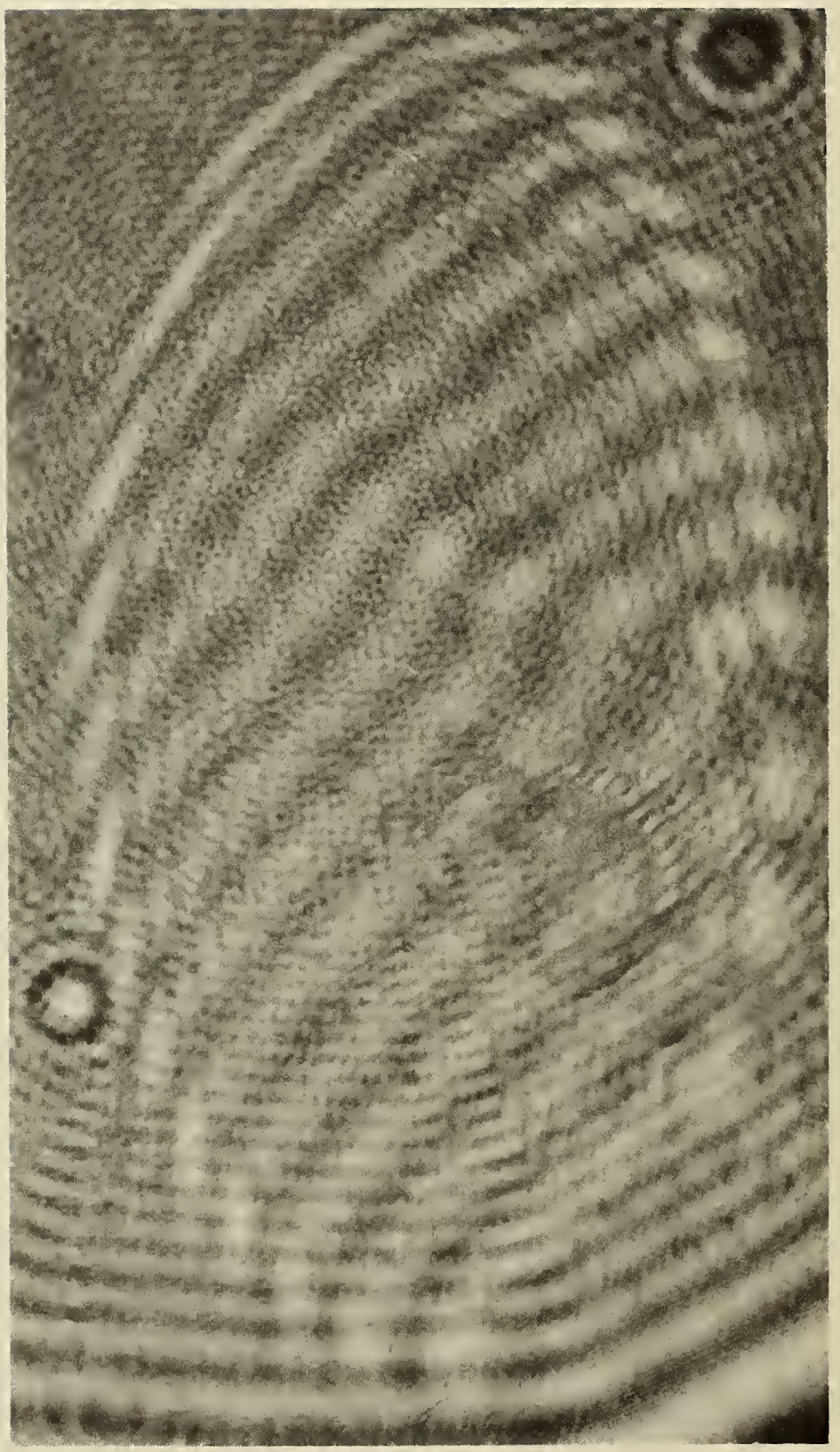

Fig. 3. Twyman-Green interferogram of first amplifier rod. The abrupt shift in the fringes indicates a sharp gradient in the optical path across the rod. 


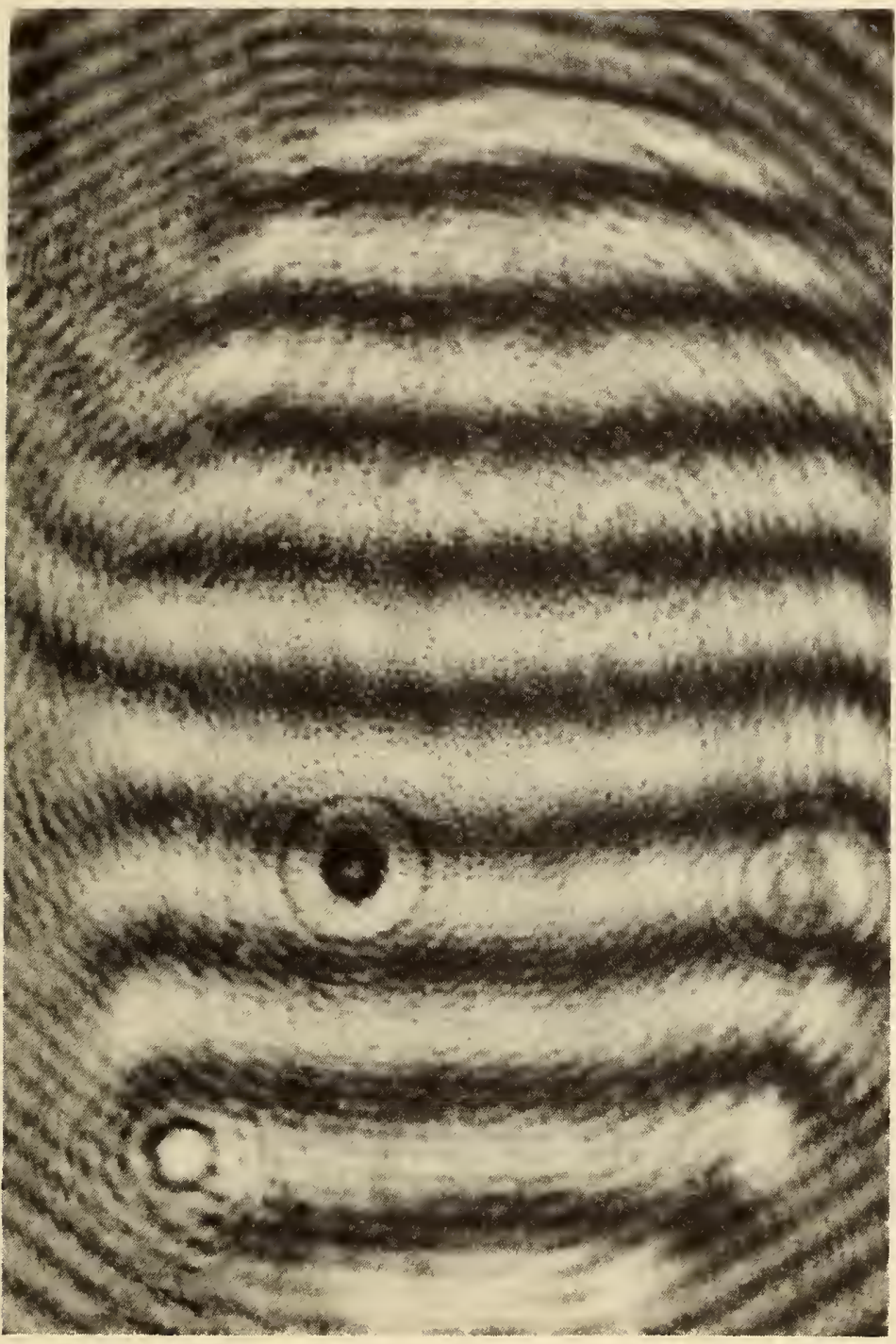

Fig. 4. Twyman-Green interferogram of second amplifier rod. The relatively evenly spaced fringes indicate good optical quality. The small spots are caused by dust. 
3.3.1.2. EFFECT of MICRODOMAINS FORMED by LIQUID/LIQUID

IMMISCIBILITY UPON the DAMAGE THRESHOLD of GLASS*

Wolfgang Haller

Inorganic Materials Division

Institute for Materials Research

and

H. Dardy

Catholic University of America

Washington, D.C. 20017

\section{Objective}

The objective of this associated project was to determine whether a correlation exists between the possible microdomain structure of glass laser rods and the intrinsic bulk damage threshold。

\section{Approach}

In a previous report(1) the question was raised whether metastable immiscibility, which is now being recognized as a widely occurring phenomenon in many glass-forming systems, plays a significant role in the mechanism of optically induced damage to laser glass rods. This question assumed even greater importance, because it was found(1) that a glass composition, close to one used in commercial laser-glasses, had a measurable liquid/liquid immiscibility gap with a critical temperature in its transformation region. It was therefore quite likely that the forming and annealing of such a glass would lead to the presence of a microdomain structure in the laser rod.

There is no doubt that microdomains cause some scattering and beam attenuation of a magnitude depending on the domain size and the

* An associated project 
difference of the index of refraction at the laser wave length between the coexistent glass phases in the laser rod. Such scattering, however, would mainly affect the lasing efficiency. Because of its diffuse, nonlocalized nature, the energy absorption associated with the microdomains would most likely not contribute to damage to the laser rod. The correctness of this assumption has been tested to the following inves tigation.

The glass used in this investigation is a sodium borosilicate of the composition (weight per cent): $\mathrm{Na}_{2} \mathrm{O}, 6.0 ; \mathrm{B}_{2} \mathrm{O}_{3}, 25.6 ; \mathrm{SiO}_{2}, 68.4$. This glass composition is at the top of the metastable immiscibility dome of the $\mathrm{Na}_{2} \mathrm{O} \cdot \mathrm{B}_{2} \mathrm{O}_{3} \cdot \mathrm{SiO}_{2}$ system(2) and its domain growth kinetics have been studied extensively(3). Domains of controlled size are introduced in the glass by heat treatments of pre-selected duration and temperature. The method of heat treatment is described elsewhere(3). After the preparation of a surface by fracture, selective etching, shading and replicating, the size of the domains can be measured by replica electromicroscopy. Another way of assessing domain size is by selectively removing one of the coexistent phases in a series of leaching treatments and subsequently measuring the pore size distribution of the remaining skelton by mercury intrusion porosimetry(4). The pore size diameter found by mercury porosimetry measures the narrow parts of the interconnected pore system. These values are about one-third of the grain diameters measured by electromicrography. The glasses used have domain diameters (from mercury intrusion-porosimetry) of $130 \AA$,

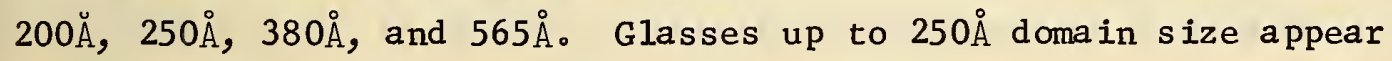
clear to the eye. Glasses of $380 \AA$ and $565 \AA$ domain size are blue-yellow opalescent. The glasses'are cut and polished to give $1 \times 3 \times 3 \mathrm{~cm}$ prismatic samples. The damage threshold of the glass samples is tested by exposing them passively to a focused laser pulse.

A nominal 10 megawatt ruby laser pulse of 15 nanoseconds duration was employed in the study. The laser operated in a single mode by means of a transmission sapphire etalon and had a cryptocyanine-methanol 
Q-switch. The expected damage site was detected by aligning a He-Ne laser coaxially through the ruby laser beam. This enabled one to inspect visually the focal region in the glass both before and after each actual laser pulse. The samples could be moved with micrometer drives in all directions. Only such regions were selected for a ruby shot which did not show any foreign particle inclusions when inspected in the coaxial He-Ne laser beam. The relatively good reproducibility is believed to be due to this pre-selection. A ballistic thermopilecalorimeter monitored the integrated energy of each pulse. Power control was achieved by rotating a Glan-Thompson prism external to the laser cavity. This permitted the laser to be uniformly pumped so as to reproduce the same Gaussian beam profile and frequency spectrum from shot-to-shot. A 9 centimeter focal length lens was used to focus the laser beam into the sample.

\section{All measurements were reproducible to within better than 10 per} cent. The experimental configuration was not changed during these runs. A relative comparison between glass systems was thus assured even if absolute energies were not exactly readable. Absolute energy measurements require that a time profile of each pulse be obtained through use of a fast photodiode and wideband oscilloscope. Such equipment was not available at the time of these measurements. Previous calibration of the laser system has shown that reproducibility from shot-to-shot can be maintained provided temperature equilibrium of the laser cavity is established. It is on this uniformity that we base our relative comparis on of measured energies even though we are not able to convert these into absolute power densities in terms of $\mathrm{MW} / \mathrm{cm}^{2}$. Multiple firing of the laser below the critical energy levels needed for damage produced no damage to the glass samples provided sufficient time for temperature equalization was allowed.

The glass sample with the smallest domain size ( $130 \AA$ ) began to fracture at 0.55 joules. The sample with the largest domain size ( $565 \AA$ ) required 0.73 joules to fracture. The other samples ranged in 
between. This difference in energy levels was probably due to beam attenuation in the more turbid samples.

In order to establish a comparison with present materials and other glasses, damage thresholds of the following glasses was determined. Fused silica and low thermal expansion borosilicate glass required both 0.55 joules. A medium thermal expansion mixed alkali borosilicate glass was slightly below 0.55 joules. Two commercial, Ne-doped laser glasses showed very low damage thresholds, approximately one-fifth of that exhibited by fused silica. Energy measurements to determine the exact cut-off were below the range of operation of the ballistic thermopile employed in the experimental system. The damage in both samples, however, was identical.

\section{Conclusion}

Under the conditions of the particular damage threshold test, an immiscible sodaborosilicate glass with submicroscopic domains displayed a threshold value similar to that for fused silica and two alkali borosilicate glasses. The damage threshold was substantially independent of domain size and was approximately five times greater than the thresholds of two commercial laser glass compositions.

\section{References}

1. J. H. Simmons and W. Haller, "Liquid-Liquid Phase Separation in a Iaser Glass", NBS Tech. Note No. 531, 31 (1970).

2. W. Haller, D. H. Blackburn, F. E. Wagstaff and R. J. Charles, "Metastable Immiscibility Surface in the System $\mathrm{Na} 20-\mathrm{B}_{2} \mathrm{O}_{3}-\mathrm{SiO}_{2}{ }^{\prime}$ J. Amer. Ceram. Soc., 53, [1] 34-39 (1970).

3. W. Haller, "Rearrangement Kinetics of the Liquid-Liquid Immiscible Microphases in Alkali Borosilicate Melts", J. of Chem. Phys. 42, 686 (1965)。 4. W. Ha1ler, "Chromatography on Glass of Controlled Pore Size", Nature, 206, 693-696 (1965). 


\subsubsection{Appendix: Trip Reports}

\subsubsection{FOREIGN TRIP REPORT}

Report by :

Dr. Herbert S. Bennett

Physicist

Nationa1 Bureau of Standards

Institute for Materials Research

Inorganic Materials Division

Physical Properties Section

Locations Visited :

University of Grenoble, France 9/13/70 - 9/17/70,

International Conference on Magnetism and Laboratoire de Spectrométric Physique

University of Rome, Italy 9/18/70, 9/21/70 - 9/23/70, Physics Department

University of Amsterdam, the Netherlands 9/25/70, Physics Department

Atomic Energy Research Establishment, Harwe11, England 9/28/70 9/30/70 and 9/6/70, Theoretical Physics Division

Roya1 Radar Establishment, Malvern, England 9/30/70 - 10/2/70, Nonlinear and Electro-Optics Section

Imperial College, Lond on, England 10/5/70, Department of Metallurgy

Purpose of Trip:

a) To attend the International Conference on Magnetism, 1970, and to visit the high magnetic field laboratory at the University of Amsterdam.

b) To visit the researchers at the University of Rome, at the 
Atomic Energy Research Establishment, Harwell, and at Imperial College, who have performed experimental and theoretical studies on color centers in ionic crystals.

c) To visit the Royal Radar Establishment, Malvern, and the University of Grenoble. Researchers at these laboratories have experienced damage or degradation in systems containing lasers and laser materials.

d) To investigate possible areas of laser damage research in which the National Bureau of Standards might make a unique and definite contribution.

e) To present a paper at the Magnetism Conference and to present formal talks at each of the above laboratories, except at Imperial College. These talks, which I gave, treated three different research areas to which I have made contributions. The areas are magnetism, damage to laser materials, and electronic states of color centers.

\section{Summary :}

This trip report summary is written in chronological order and not according to the subject areas.

\section{Internationa1 Conference on Magnetism}

The 1970 International Magnetism Conference was extremely large and suffered from the usual problems common to large meetings with parallel sessions. The single most important point from this conference for me was to learn that the researchers in Prof. Prigogine's group at the University of Brussels are working on an expansion technique from which the transport properties (e.g., spin diffusion and thermal conductivity) for magnetic systems near their critical points may be computed. Prof. Prigogine discussed an unpublished calculation on such transport properties. His group found that the contributions of the various modes of the system are similar to each other to all orders of the expansion for a class of mean-field models. Thus, the usual perturbation series does not converge. In fact, a renormalization procedure is required to describe the behavior near the critical point. 
The papers presented in the session on the "Critical Phenomena" indicated that progress has been made since the last International Conference on Magnetism (Boston 1967) in applying scaling concepts to critical phenomena such as the second order ferromagnetic and antiferromagnetic phase transitions. Prof。Gaunt (King's College, London) reported on the considerable amount of evidence which supports scaling concepts for the equation of state in the critical region. He gave evidence that the scaling function which occurs in the equation of state depends on the lattice dimension and not on lattice structure. Also, by examining the higher order terms in the equation of state, one can assess the region of validity of the scaling law form。

2. Laboratoire de Spectrometrie Physique, University of Grenoble

I discussed with Dr。J. Lajzerowicz (Grenoble) the second harmonic light scattering by domains in ferroelectric materials such as triglycine sulfate and KDP. The latter material is used as the $Q$ switch in the NBS Nd-glass laser. If domains are induced in the KDP $Q$ switch, then inhomogeneities in the laser beam due to the generation of second harmonic light, which will reduce the spatial intensity at the fundamental frequency in the vicinity of a domain wall, might arise. Dr. Lajzerowicz believes that if the electric field which induces the dipole moments in the $\mathrm{KDP} Q$ switch is perpendicular to the optic axis, then the generation of second harmonic light should not occur. Hence, it is most important for the NBS laser effort to determine that these conditions obtain. At present, the Nd-glass laser has inhomogeneities, and we should make certain that the electric field is perpendicular to the optic axis of our KDP Q switch. Dr. Lajzerowicz also pointed out the importance of having a single crystal of $\mathrm{KDP}$ for the $\mathrm{Q}$ switch. He feels that polycrystalline KDP would certainly introduce inhomogeneities in the intensity of the laser beam.

3. University of Rome, Physics Department

$\mathrm{Dr}$ 。P. Perfelti is developing heterojunctions of GaAs and $\mathrm{PbS}$. Such junctions may be used as pressure sensitive detectors for $7 \mu$ to 
$14 \mu$ radiation. The $\mathrm{CO}_{2}$ laser radiates at $10.6 \mu$. The atmosphere also exhibits relatively little absorption for this same range of wavelengths.

Prof. G. Chiarotti and Prof。G。 Margaritondo recently have measured severa 1 properties of the relaxed and unrelaxed $\mathrm{F}$-center states in $\mathrm{KCl}, \mathrm{KBr}, \mathrm{RbCl}$, and $\mathrm{NaCl}$. They studied the $\mathrm{F}$ center in absorption and also in emission. In particular, the Stark effect in the $F$ center absorption has been observed in the above mentioned alkali halides. Changes of the absorption coefficient due to the electric field have been measured as a function of photon energy. From these data and by using the method of moments given by Slichter (University of I1linois) the energy difference between the $2 \mathrm{~s}$ and $2 \mathrm{p}$ levels and the dipole matrix element $\langle 2 s|z| 2 p\rangle$ have been evaluated. These are unpublished results of which $I$ was not aware when I was writing my most recent paper on the $\mathrm{F}$ center. In that paper, I considered only the Stark effect for emission. I plan now, as the result of my conversations with Prof. Chiarotti and Prof. Magaritondo, to compute the Stark effect for absorption.

I learned also that in addition to reporting my $F$ center lifetimes in terms of the ratio of dipole matrix elements, I should have reported the values of the dipole matrix elements for absorption and emission. These values are available and the researchers at the University of Rome have suggested that I publish them in a separate paper. I underestimated their worth to experimentalists and did not include them in my most recent paper in an effort to reduce the length of that paper.

\section{University of Amsterdam, Physics Department}

The University of Amsterdam has a new high magnetic field laboratory. The installation is equipped with a computer determining the field strength as a function of time. This permits a very sensitive test of the proportionality between the magnetic moment and the field strength in paramagnetic substances. Dr. R. Gersdorf and others in his 
group described the magnetic field installation. It has been constructed to produce a field which increases from 0 to $32,6 \mathrm{~T}$ in about $250 \mathrm{~ms}$, remains constant at $32.6 \mathrm{~T}$ for $60 \mathrm{~ms}$ and then decreases to zero in seven equal steps of about $80 \mathrm{~ms}$ each. Experiments can be performed at $4^{\circ} \mathrm{K}$. They have detected deviations from linearity of $\mathrm{Pd}$ metal at $4^{\circ} \mathrm{K}$. They find that the magnetization $M=\chi H\left(1+\beta H^{2}\right)$, where $\chi$ is the low field limit to the susceptibility, $H$ the magnetic field, and $\beta=(6.1 \pm 1.0) \times 10^{-16} \mathrm{~T}^{-2}$. Hence, they argue that a sensitivity of 1 part in $10^{7}$ is possible with their new installation.

I consulted also with Prof. de Chatel at the University of Amsterdam on his problem of understanding the highly damped but propagating modes in magnetic spin systems.

Prof.P.de Chatel is attempting to construct a theory for the very weak itimerant ferromagnetism in the binary alloys $\mathrm{Ni}_{3} \mathrm{Ga}$ and $\mathrm{Ni}_{3} \mathrm{Al}$. He would like this theory to be valid in the vicinity of the transition temperature $T_{c}$ and to include the highly damped propagating modes. Such modes frequently are called paramagnons. He has computed the response of these systems to a weak external magnetic field at temperatures less than the critical temperature. We discussed the possible analogy between the poorly propagating modes around the critical temperature which I found in the Heisenberg systems and the spin wave spectrum of itinerant electrons which Prof. de Chatel believes exists in these binary alloys, assuming that the alloys $\mathrm{Ni}_{3} \mathrm{Ga}$ and $\mathrm{Ni}_{3} \mathrm{Al}$ are free from the complications caused by composition clusters (local deviations from stoichiometric composition).

\section{Atomic Energy Research Establishment - Theoretical Physics Division}

Dr. Marshall Stoneham and I are working on a theory to treat the long lifetime of the relaxed excited state of the F center in $\mathrm{KCl}$ and $\mathrm{NaCl}$. Such studies are related to the speed with which photochromic materials may be switched. The problem is to determine how the local 
electric field varies from one $F$ center to another. I have recently developed a theory which gives the lifetime as a function of the at present unknown local electric field. Dr. Stoneham has computed recently the fluctuating electric fields for the dynamic and static Jahn-Teller effects. We feel that the elements of his work can be applied to my $F$ center theory. While at the Theoretical Physics Division we thought about how to accomplish this. We have ideas on this now but the mechanics for developing the necessary theoretical techniques are not straightforward and will require considerable more thought. A gross simplification of our present understanding is as follows. Due to the local vibrational modes of the lattice a distribution of $\mathbf{F}$ center types exists. Some $\mathrm{F}$ centers experience large electric fields and other experience only small electric fields. So the lifetime measured in the laboratory is a nonlinear average over the distribution of $F$ center types. The problem is to compute the distribution of $\mathrm{F}$ center types. We plan to collaborate on this problem in the future.

I discussed with Dr. Alan Lidiard the changes which have occurred at the Atomic Energy Research Establishment and in particular the changes which his Theoretical Physics Division have undergone since 1966. Many researchers now apply their knowledge in theoretical physics to very practical problems of private industry and government. One example is the control and reduction of fuel cell swelling in fast breeder reactors.

6. Royal Radar Establishment, Malvern

Dr. Ken F。 Hulme was my host and arranged a most informative visit for me.

Dr. Hulme is in charge of the Nonlinear and Electro-Optics Section at Royal Radar Establishment. Their original aim was to develop new materials for the variable part of the spectrum. But they soon became involved with the optical mixing crystals. First they grew KDP, ADP 
and triglycine sulfate and then $\mathrm{Ag}_{3} \mathrm{AsS}_{3}, \mathrm{LiNbO}_{3}, \mathrm{Ba}_{2} \mathrm{NaNb}_{5} \mathrm{O}_{15}$, and $\mathrm{LiIO}_{3}$.

They are now interested in the coumarin derivatives. Such derivatives have been used previously as $Q$ switches for ruby lasers. But now single crystals of the coumarin derivatives may be used for frequency doubling the beam from neodymium glass and neodymium YAG lasers. Articles appearing during the past year in Applied Physics Letters claim that single crystals of coumarin derivatives are highly resistant to optically induced damage.

other recent nonlinear optical materials which they have studied are GdHg (NS) ${ }_{x}$, lithium formate, $\mathrm{Te}_{2}$, Yt aluminate, Ho fluoride, and FAP. Dr. Hulme's group now is phasing out research on new materials and concentrating more on how best to use presently available materials in electro-optical devices ( $Q$ switches, up-conversion and infrared imaging to the visible.)

Researchers at NBS are growing crystals of pyrargyrite $\left(\mathrm{Ag}_{3} \mathrm{SbS}_{3}\right)$. This crystal is related to proustite $\left(\mathrm{Ag}_{3} \mathrm{AsS}_{3}\right)$ and has nonlinear optical applications from $1 \mu$ to $10 \mu$. Pyrargyrite appears more promising than proustite because pyrargyrite has a damage threshold which is much further from the nonlinear optical threshold than that for proustite. It also should have better optical qualtities. Because the techniques for growing pyrargyrite are similar to those for growing proustite crystals, I was particularly interested in their results on proustite. Researchers at RRE have had considerable experience in growing single proustite crystals for up-conversion, which requires large crystals. Using a modified Bridgeman technique they have grown crystals $2.6 \mathrm{~cm}$ in diameter by $1 \mathrm{~cm}$ thick. They have used the stockbarger method to study crystal growing for the following crystals, $\mathrm{AgGaS}_{2}$, $\mathrm{CdGa}_{2} \mathrm{~S}_{4}$, $\mathrm{ZnGa}_{2} \mathrm{~S}_{4}, \mathrm{ZnIn}_{2} \mathrm{~S}_{4}$, and $\mathrm{AgInS}_{2}$. The Stockbarger method has been used also to grow proustite boules $15 \mathrm{~mm}$ long by $12 \mathrm{~mm}$ in diameter at the growth rate of $4 \mathrm{~mm}$ per day. Controlling the stoichiometry of proustite is difficult and still uncertain. They use excess sulfur in some cases to attempt to control the stoichiometry of proustite. 
The Royal Radar Establishment has a materials information center. The center, called Electronic Materials Unit, exists to make available research quantities of those electronic materials developed by the Materials Research Division of which Dr. Beardsley is the Chief, which are not otherwise available because of their novelty or of the difficulty of their preparation.

\section{Imperial College, Department of Metallurgy}

I took this opportunity to visit Nancy Tighe, who is on a leave of absence from the National Bureau of Standards to work with Prof Peter Swann on the $1 \mathrm{MEV}$ electron microscope at Imperial College. This $1 \mathrm{MEV}$ electron microscope is in the final stages of being installed in a laboratory which was previously used for hydraulic studies. The microscope is an impressive $21 / 2$ stories high. Prof. Swann and Nancy Tighe plan to study the reduction of hematite $\left(\mathrm{Fe}_{2} \mathrm{O}_{3}\right)$ to magnetite $\left(\mathrm{Fe}_{3} \mathrm{O}_{4}\right)$ and then to Fe0. At present the $\mathrm{Fe}_{2} \mathrm{O}_{3}$ and $\mathrm{Fe}_{3} \mathrm{O}_{4}$ samples do not thin as easily as the previous $\mathrm{Al}_{2} \mathrm{O}_{3}$ samples with which Nancy Tighe has worked at NBS. Relatively thin samples less than $50 \mu$ are required even for the transmission experiments planned with the $1 \mathrm{MEV}$ electron microscope. In addition, they are concerned about obtaining good magnetite crystals and may ask the National Bureau of Standards to provide them with such crysta1s.

Prof. Boswarva and Dr. Tharmalingam, who are also at Imperial College, have calculated theoretically the formation energies of Schottky and Frenkel defects in calcium fluoride, uranium oxide, and cerium oxide. Their model for calcium fluoride is similar to the model which Dr. Alan Franklin at NBS has used。Using Dr. Franklin's calcium fluoride results to back their model, they then proceed to do the fluorite-structured oxides $\mathrm{UO}_{2}$ and $\mathrm{CeO}_{2}$. They find that to 0 order, 1st order and 2nd order, anion Frenkel pairs are the intrinsic defects in calcium fluoride. However, the 0 order calculations predict that anion Frenkel pairs are the intrinsic defects in $\mathrm{UO}_{2}$ and higher order calculations predict that the Schottky defects are the intrinsic defects. 
I also spoke with Prof. D. Holt about las er beam uniformity problems with GaAs lasers. Such lasers are noted for their hot spots (fluctations) in the spatial intensity of the laser beam. A GaAs laser is a $\mathrm{p}-\mathrm{n}$ junction for which the $\mathrm{p}$ layer is GaAs doped with $\mathrm{Zn}$ and the $\mathrm{n}$ layer is GaAs doped with Se, Te, or Si. The two different dopants change the crystal parameters somewhat and lead to incomplete interstitial lattice planes near the junction. Prof. Holt has found a correlation between laser performance and the number of defects near the $\mathrm{p}-\mathrm{n}$ junction.

At all of the laboratories which I visited, I asked whether they had any staff members who were familiar with damage or degradation in any of the laser materials. In particular after visiting the Royal Radar Establishment, University of Grenoble, and Imperial College, I have formed the subjective opinion that there is 1ittle, if any, effort in Western Europe to improve the characterization of laser beams for damage measurements. The science of measuring damage thresholds at present needs considerable improvement. Even at the Royal Radar Establishment there is not a group which plans detailed experiments to determine the spatial uniformity, the temporal properties, and the frequency spectrum of the laser beams used in studying damage measurements. Once these parameters are known it is also important to improve them. This is an area of laser technology which has been neglected and is the area in which the National Bureau of Standards can have the greatest impact if its program to develop a damage test facility is successful. 


\subsubsection{DOMESTIC TRIP REPORT}

Report by :

Dr. Herbert S. Bennett

Physicist

National Bureau of Standards

Institute for Materials Research

Inorganic Materials Division

Physical Properties Section

Locations Visited:

Lawrence Radiation Laboratory, Livermore, 11/9/70

Microwave Laboratory, Stanford University, 11/10/70

U. S. Navy Postgraduate School, Monterey, 11/12/70 - 11/13/70

Hughes Research Laboratories, Malibu, 11/16/70 - 11/17/70

Purpose of Trip:

1. To visit and consult with the researchers at the above laboratories, who have experienced damage or degradation in systems containing lasers and laser materials.

2. To investigate possible areas of laser damage research in which the National Bureau of Standards might make a unique and definite contribution.

3. To present invited colloquia at the Lawrence Radiation Laboratory, the U. S. Naval Postgraduate School, and the Hughes Research Laboratories.

Some of the information which I acquired during visits to laboratories concerned with damage to laser materials is reported here. These laboratories and my host at each laboratory were: The Lawrence Radiation Laboratory, Livermore, (Dr。J。Swain, 9 Nov.), the Microwave Laboratory, Stanford University (Prof. Robert Byer, 10 Nov.), and Hughes Research Laboratories, Malibu, (Dr. Conrad Giuliano, 17 Nov.)。

This trip is written in chronological order. 
1. Lawrence Radiation Laboratory, Livermore, 11/9/70, Dr. J。Swain。

Dr。J. Swain was my host. Researchers in Dr. Swain's group at LRL, Livermore, have constructed a 15 element-5 inch disc laser and are planning to build a 12 inch disc laser. These lasers contain neodymiumdoped laser glass and radiate at the $1.06 \mu$ neodymium wavelength. The 15 element-5 inch disc laser produces a laser beam with an energy of 200 $\mathrm{J}$ over $50 \mathrm{~cm}^{2}$ in a lns pulse. If the laser damage thresholds of the optical components can be increased, the present configuration has sufficient energy storage to produce a laser beam with $1000 \mathrm{~J}$ in a 1 ns pulse. I also visited this laboratory in June 1969. Since that time researchers have encountered additional damage problems. Operating at lower power densities than they now do, the researchers experienced in early 1969 only surface damage on the non-lasing components in the laser beam. Their attempts to exceed the present limit of $400 \mathrm{~J}$ over $50 \mathrm{~cm}^{2}$ in a $1 \mathrm{~ns}$ pulse usually lead to surface damage of the dielectric-coated mirrors and to self-focussing damage in the laser rods. Using commercially-available high quality optical glass, the find that the damage due to inclusions becomes negligible. In order to solve the surface damage of the dielectric-coated mirrors, they are replacing the mirrors with prisms constructed from borosilicate crown glass BK 7 . They hope that the bulk extrinsic and intrinsic damage thresholds for prisms will be greater than the surface damage threshold of the prisms and of the presently used mirrors by at least a factor of two. Because meaningful data on the damage thresholds of optical materials at $1.06 \mu$ do not exist, the researchers at Livermore will have to experiment with several materials and techniques in their attempts to achieve the $1000 \mathrm{~J}$ pulses for which their present configuration has been designed.

Dr. Swain has devoted considerable effort and time to characterizing the temporal and spatial properties of the laser beam. The Lawrence Radiation Laboratory 5 inch disc laser contains a very complex oscillator section to achieve a reproducible beam which exhibits Gaussian behavior in time and in space. He has determined the uniformity of the nine KDP Pockel cells (Q-switches). These Q-switches 
together with apertures are used to control the laser beam. In addition, because every time the laser beam is apertured or pulse shaped the energy content of the beam decreases, the researchers have a total of 9 additional amplifier rods in the complex oscillator section with feedback to control spatial and temporal properties of the laser beam.

2. Microwave Laboratory, Stanford University, 11/10/70, Prof。 Robert Byer.

Professor Robert Byer directs the research on the non-linear laser materials effort at the Microwave Laboratory. His group produces laser materials and measures the non-linear optical properties of potentially important crystals for laser applications. During the past year, the Stanford researchers have grown from solutions crystals of $\mathrm{LiIO}_{3}$ which are about $3 \mathrm{~cm}$ in diameter and $5 \mathrm{~cm}$ long. These crystals of $\mathrm{LiIO}_{3}$ are uniaxial, polish easily, and have non-linear coefficients which are about nine times larger than the non-linear coefficients for KDP. They also have surface damage thresholds of about $100 \mathrm{MN} / \mathrm{cm}^{2}$. $\mathrm{LiIO}_{3}$ is a promis ing new laser material. Other laser materials which have been examined are proustite and dimethyl-sevenethyl-coumarin. Because the surface damage threshold for proustite is very close to its parametric threshold, Prof. Byer does not consider proustite to be a suitable laser material. The various damage and non-linear optical thresholds for the related pyargyrites are not known. Measuring such thresholds for pyargyrite $\left(\mathrm{Ag}_{3} \mathrm{SbS}_{3}\right)$ is a worthwhile research project. The coumarin crystals, which were grown at Stanford from coumarin derivatives dyes supplied by a commerical source, have a high surface damage threshold. However, the optical quality of present crystals is very poor. The crystals are yellow. If coumarin dyes can be purified substantially, then dimethyl-sevenethyl-coumarin would be a very promising laser material.

Prof. Byer and one of his students have completed a quantitative study on the advantages and disadvantages of Raman, resonance, and absorption scattering for air pollution measurements. I have called $\mathrm{Dr}$. McNesby's attention to this work。 
3. Hughes Research Laboratories, Malibu, 11/16/70 - 11/17/70 Dr. Giuliano.

Dr. Giuliano has completed the first in a series of intrinsic bulk damage threshold measurements on ruby. His test apparatus is an improved ruby laser which is Q-switched by a solution of cryptocyanine and which operates very reliably (95\%) in a single TEM ${ }_{\text {oo }}$ mode. The improvements were required in order to achieve negligible change in the laser beam parameters from one pulse to another pulse and to monitor the space, time and spectral properties of the laser beam for each damage threshold measurement. The spatial properties of the beam are controlled by apertures made from machine die for wire pulling, a resonance reflector (two uncoated Fabrey-Perot plates) and the saturable dye. The resonance reflector is heated to change the separation between its plates and thereby to aid in spatial mode control. A MgO diffuser in a nineelement camera is employed to determine the spatial uniformity of the laser beam at several locations along the laser beam path. Coated Fabrey-Perot plates are used to monitor the frequency spectrum and the number of longitudinal modes. This laser produces a beam having an energy of about $15 \mathrm{~mJ}$, a pulse length of $20 \mathrm{~ns}$, and a beam radius of $1 \mathrm{~mm}$ ( $1 / \mathrm{e}$ for the electric field)。

Dr. Giuliano has studied the thresholds for the appearance of the filamentary damage tracks (intrinsic bulk damage) as a function of focal length of the lens which focuses the ruby laser beam inside the test samples. The samples are ruby samples having different $\mathrm{Cr}$ concentration and sapphire. The focussing lens is made from fused silica, is diffraction limited, and is designed to minimize the longitudinal spherical aberration. In addition, he has determined the time behavior of the damage tracks by means of a streak camera. The filamentary tracks begin inside the sample and grow toward the entrance face of the sample. The growth velocity has also been determined as well as the spectral content of the light scattered by the damage tracks. 
I also spoke to Dr. Gentile (Hughes Research Laboratories, Malibu, California) about growing crystals of $\mathrm{Ag}_{3} \mathrm{AsS}_{3}$ (proustite) and $\mathrm{Ag}_{3} \mathrm{SbS}_{3}$ (pyrargyrite). He has grown these two crystals by a modified Bridgman technique and by a Czochralski technique. The latter method is not recommended. Even though an $\mathrm{Ag}-\mathrm{Sb}$ alloy sinks in the melt so that the proper composition can be pulled, excess sulfur occurs and presents an exceedingly difficult disposal problem. The Bridgman techniques are more promising and have a greater potential for improvement. He has also obtained by a modified Bridgman technique single crystals of $\mathrm{Ag}_{3} \mathrm{AsS}_{3}$ (proustite). He has not been able to grow single crystals of $\mathrm{Ag}_{3} \mathrm{SbS}_{3}$ (pyrargyrite). The starting materials for the pyrargyrite studies were supplied by a commercial source and may not be of the best purity. Also, pyrargyrite is more sensitive to oxygen contamination than proustite. Proustite and pyrargyrite are nonlinear optical materials which have applications from $.6 \mu$ to $10 \mu$.

In conclusion, during the past eighteen months, the researchers at the above three laboratories have demonstrated successfully ways to control and to monitor the laser beam parameters. These efforts should form the basis for additional techniques by which reproducible and meaningful damage threshold measurements can be made in the future.

4. U. S. Navy Postgraduate Schoo1, Monterey, 11/12/70 - 11/13/70 Prof. Neighbours。

Prof. Neighbours was my host at the Naval Postgraduate School. He has had considerable experience in ultrasonic problems in solids. His group is thinking about setting up a small laser facility with which to study the interactions among acoustic phenomena and laser beams. After presenting my colluquium, I consulted with them as to what were some of the more challenging and interesting physics problems associated with sound and light experiments. 

Latest developments in the subject area of this publication, as well as in other areas where the National Bureau of Standards is active, are reported in the NBS Technical News Bulletin. See following page. 


\section{HOW TO KEEP ABREAST OF NBS ACTIVITIES}

Your purchase of this publication indicates an interest in the research, development, technology, or service activities of the National Bureau of Standards.

The best source of current awareness in your specific area, as well as in other NBS programs of possible interest, is the TECHNICAL NEWS BULLETIN, a monthly magazine designed for engineers, chemists, physicists, research and product development managers, librarians, and company executives.

If you do not now receive the TECHNICAL NEWS BULLETIN and would like to subscribe, and/or to review some recent issues, please fill out and return the form below.

Mail to: Office of Technical Information and Publications National Bureau of Standards

Washington, D. C. 20234

Name

Affiliation

Address

City State Zip

Please send complimentary past issues of the Technical News Bulletin.

Please enter my 1-yr subscription. Enclosed is my check or money order for $\mathbf{\$ 3 . 0 0}$ (additional $\$ \mathbf{1 . 0 0}$ for foreign mailing). Check is made payable to: SUPERINTENDENT OF DOCUMENTS. TN 574 
FORM NBS-114A $(1-71)$

U.S. DEPT. OF COMM. BIBLIOGRAPHIC DATA SHEET

4. TIT LE AND SUBTITLE

ARPA-NBS PROGRAM OF RESEARCH ON HIGH TEMPERATURE MATERIALS AND LASER MATERIALS, Reporting Period July 1 to December 31 , 1970

$\begin{aligned} & \text { 1. PUBLICATION OR REPORT NO. } \\ & \text { NBS TN } 574\end{aligned}$
$\begin{aligned} & \text { 2. Gov't Accession } \\ & \text { No. }\end{aligned}$
$\begin{aligned} & \text { RESEARCH ON HIGH TEMPERATURE MATERIALS } \\ & \text {, Reporting Period July } 1 \text { to December 31, }\end{aligned}$

7. AUTHOR(S)

A. D. Franklin and H. S. Bennett (Edited by)

9. PERF ORMING ORGANIZATION NAME AND ADDRESS

\author{
NATIONAL BUREAU OF STANDARDS \\ DEPARTMENT OF COMMERCE \\ WASHINGTON, D.C. 20234
}

5. Publication Date

April 1971

6. Performing Organization Code
12. Sponsoring Organization Name and Address

Office of Materials Sciences

Advanced Research Projects Agency

1400 Wils on Boulevard

Arlington, Virginia 22209
8. Performing Organization

10. Project/Task/Work Unit No. 3000400

11. Contract/Grant No.

ARPA Order 373-62

13. Type of Report \& Period Covered Interim

Jul 1 to Dec 31,1970

14. Sponsoring Agency Code

15. SUPPLEMENTARY NOTES

16. ABSTRACT (A 200-word or less factual summary of most significant information. If document includes a significant bibliography or literature survey, mention it here.)

Progress reports are given for projects on the growth of ultra-pure $\mathrm{Al}_{2} \mathrm{O}_{3}$ crystals, the development of a mass spectrometer-based sectioning technique for measuring oxygen diffusion in oxides, the development of a precision facility for measuring the threshold energy in a laser beam producing damage in a transparent substance, and the study of the factors influencing this damage threshold in glass.

17. KEY WORDS (Alphabetical order, separated by semicolons)

$\mathrm{Al}_{2} \mathrm{O}_{3}$; crystal growth; damage threshold; glass; high temperature materials; 1aser;

oxides; oxygen diffusion; pure materials; sapphire.

18. AVAILABILITY STATEMENT

$\mathrm{X}$ UNL IMITED.

FOR OFFICIAL DISTRIBUTION. DO NOT RELEASE TO NTIS. 19. SECURITY CLASS
(THIS REPORT)

UNCL ASSIF IED

20. SECURITY CLASS (THIS PAGE)

UNCL ASSIFIED
21. NO. OF PAGES 44

22. Price

.50 



\section{PERIODICALS}

JOURNAL OF RESEARCH reports National Bureau of Standards research and development in plyysics, nlathenatics, chemistry, and engineering. Comprehensive scientific papers give complete details of the work, including laboratory data, experimental procedures, and theoretical and mathematical analyses. Illustrated with photographs, drawings, and charts.

Published in three sections, available separately:

\section{Physics and Chemistry}

Papers of interest primarily to scientists working in these fields. This section covers a broad range of physical and chemical research, with major emphasis on standards of physical measurement, fundamental constants, and properties of matter. Issued six times a year. Annual subscription: Domestic, $\$ 9.50$; foreign, $\$ 11.75^{*}$.

\section{Mathematical Sciences}

Studies and compilations designed mainly for the mathematician and theoretical physicist. Topics in mathematical statistics, theory of experiment design, numerical analysis, theoretical physics and chemistry, logical design and programming of computers and computer systems. Short numerical tables. Issued quarterly. Annual subscription: Domestic, $\$ 5.00$; foreign, $\$ 6.25^{*}$.

\section{- Engineering and Instrumentation}

Reporting results of interest chiefly to the engineer and the applied scientist. This section includes many of the new developments in instrumentation resulting from the Bureau's work in physical measurement, data processing, and development of test methods. It will also cover some of the work in acoustics, applied mechanics, building research, and cryogenic engineering. Issued quarterly. Annual subscription: Domestic, $\$ 5.00$; foreign, $\$ 6.25 *$.

\section{TECHNICAL NEWS BULLETIN}

The best single source of information concerning the Bureau's research, developmental, cooperative and publication activities, this monthly publication is designed for the industry-oriented individual whose daily work involves intimate contact with science and technology-for engineers, chemists, physicists, research managers, product-development managers, and company executives. Annual subscription: Domestic, $\$ 3.00$; foreign, $\$ 4.00^{*}$.

* Difference in price is due to extra cost of foreign mailing.

\section{NONPERIODICALS}

Applied Mathematics Series. Mathematical tables, manuals, and studies.

Building Science Series. Research results, test methods, and performance criteria of building materials, components, systems, and structures.

Handbooks. Recommended codes of engineering and industrial practice (including safety codes) developed in cooperation with interested industries, professional organizations, and regulatory bodies.

Special Publications. Proceedings of NBS conferences, bibliographies, annual reports, wall charts, pamphlets, etc.

Monographs. Major contributions to the technical literature on various subjects related to the Bureau's scientific and technical activities.

National Standard Reference Data Series. NSRDS provides quantitative data on the physical and chemical properties of materials, compiled from the world's literature and critically evaluated.

Product Standards. Provide requirements for sizes, types, quality and methods for testing various industrial products. These standards are developed cooperatively with interested Government and industry groups and provide the basis for common understanding of product characteristics for both buyers and sellers. Their use is voluntary.

Technical Notes. This series consists of communications and reports (covering both other agency and NBS-sponsored work) of limited or transitory interest.

Federal Information Processing Standards Publications. This series is the official publication within the Federal Government for information on standards adopted and promulgated under the Public Law 89-306, and Bureau of the Budget Circular A-86 entitled, Standardization of Data Elements and Codes in Data Systems.

Consumer Information Series. Practical information, based on NBS research and experience, covering areas of interest to the consumer. Easily understandable language and illustrations provide useful background knowledge for shopping in today's technological marketplace.

NBS Special Publication 305, Supplement 1, Publications of the NBS, 1968-1969. When ordering, include Catalog No. C13.10:305. Price \$4.50; foreign, $\$ 5.75$.

Order NBS publications from:

Superintendent of Documents

Government Printing Office

Washington, D.C. 20402 
U.S. DEPARTMENT OF COMMERCE

WASHINGTON, D.C. 20230

OFFICIAL BUSINESS

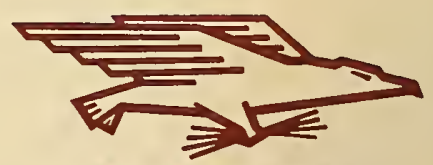

POSTAGE AND FEES PAID

U.3. DEPARTMENT OF COMMERCE

PENALTY FOR PRIVATE USE, $\$ 300$ 